\title{
Effects of $p$-Cresol on Photosynthetic and Respiration Rates of a Filamentous Green Alga (Spirogyra)
}

\author{
Jean Stout ${ }^{1}$ and Susan S. Kilham² \\ ${ }^{1}$ Department of Zoology, Michigan State University, East Lansing, MI 48824, \\ and ${ }^{2}$ Division of Biological Sciences, University of Michigan, \\ Ann Arbor, MI 48109
}

Development of coal gasification plants in the United States for the generation of electrical power (SPENCER et al. 1982) may increase the probability of accidental spills of coal-derived phenols and monohydric cresol isomers into streams and rivers. Although Europe has experienced several accidental spills from coal fired electrical plants and phenol producing plants (ALABASTER et a1. 1973), more information is needed as to biological effects of cresols in aquatic ecosystems. This paper presents data on physiological effects of a phenol derivative, p-cresol, on physiological rates of a major biotic component, Spirogyra sp., in many slow-moving, low gradient streams in the United States.

Prior to the present studies, we observed damage to the filamentous green alga after it had been exposed to p-cresol in outdoor experimental stream channels at the Montice11o, Minnesota E.P.A. Research Laboratories. Along with algal color 1oss, severe drops in dissolved oxygen occurred. Because the channels are highly autotrophic and are dominated by the primary producer, Spirogyra, we designed field experiments in 1980 to determine whether its respiratory and/or photosynthetic rates were altered by $\mathrm{p}$-cresol at the concentration ( $8 \mathrm{ppm}$ ) used in the prolonged dose $(48 \mathrm{~h})$. If oxygen production by the algae was lowered in the presence of $p$-cresol, then the damage to the algae could have contributed to the observed depression of dissolved ozygen (D.0.) in the channel during the continuous dose. The following year, additional experiments were performed where concentrations of p-cresol were varied in order to determine the dosage lethal to the algae.

\section{MATERTALS AND METHODS}

\section{Site}

A set of open channel experimental streams was built by U.S. Environmental Protection Agency (E.P.A.) near Monticello, Minnesota in 1973. Four of the channels were modified in 1979 for closed-system operation by Michigan State University under a grant from E.P.A. The resultant two closed-cycle streams were each $3.4 \mathrm{~km}$ long and $4 \mathrm{~m}$ wide, with alternating pools and riffles ranging in depth from 0.5 to $1.0 \mathrm{~m}$. Continuous monitoring, including p-cresol concentration, dissolved oxygen, $\mathrm{pH}$, temperature, velocity, depth and solar radiation, was done along the stream channels. From 9 August (at 1000 h) of 1980, one channel was continously dosed with $8 \mathrm{ppm} 99+\%$ pure p-cresol 
p-cresol (Aldrich Chemical Co.) for $48 \mathrm{~h}$. Results of that dosing led us to perform two types of experiments.

Experimental procedures, 1980

Water was collected from the undosed channel and vacuum-filtered with an 0.8 micron $44 \mathrm{~mm}$ dianeter membrane filter. Spirogyra sp. was taken from the undosed channel and rinsed several times with filtered stream water to remove aquatic invertebrates. Several strands were added to a $25 \mathrm{~mL}$ graduated cylinder until $5 \mathrm{~mL}$ of water was displaced (about 15 $\mathrm{mg} \mathrm{DW})$. Then, filtered water and the alga were added to a 300 $\mathrm{mL}$ B.0.D. bottle. This was repeated for a total of four replicate light and two replicate dark bottles. Bottles were placed in the previously dosed channel $2 \mathrm{~h}$ after which time they were brought back to the laboratory and dissolved oxygen values were determined by the azide modification of the Winkler method (HITCHMAN 1978). (Initial dissolved oxygen values were determined from randomly sampled bottles for each treatment just prior to each field experiment. Three subsamples bottle from each bottle were titrated and the average value recorded. Then algae at the bottom of the bottles were filtered, dried at $100 \mathrm{C}$ overnight and weighed to the nearest $0.1 \mathrm{mg}$. In the experiments where p-cresol was added to some of the bottles, freshly prepared p-cresol at a concentration of $8 \mathrm{ppm}$ was made up in filtered stream water from the non-dosed channel. In that experimental set, treatments included algae with and without p-cresol and filtered, autoclaved water with and without $\mathrm{p}$-cresol to separate biological from non-biological dissolved oxygen changes by p-cresol.

Experimental procedures, 1981 .

Dr. Don Mount and Ms. Teresa Norberg of the E.P.A. Laboratories at Duluth, Minnesota performed the following experiments at the Monticello site: On 15 July they put clumps of Spirogyra into each of six wire baskets and put one basket each of five concentrations of p-cresol in stream water (71, $34,14,4.6$ and $0.9 \mathrm{p} \mathrm{pm}$ ). Water temperatures throughout the experiments ranged from 21.7 to $29.4 \mathrm{C}$. The final basket was used as the control for the experiments. The algae was allowed to remain in stream water with and without p-cresol for three hours; experiments were repeated three times: 0630 to 0930; 0800 to 1100 and from 1345 to $1645 \mathrm{~h}$. After three hours, all baskets were placed in the control tank. Algae from each treatment ( $3 \mathrm{~mL}$ displacement) were put in 250-mL B.0.D. bottles and placed directly in the channel for one hour. Light intensity was the same for the control as for the experimental bottles. Dissolved oxygen concentrations were determined with a YSI Model 57 dissolved oxygen meter.

\section{RESULTS}

In the light bottle - dark bottle experiments, the net 
production of oxygen by Spirogyra for control bottles averaged $0.084 \pm 0.028 \mathrm{mg} 0_{2} / \mathrm{mg} \mathrm{DW} . \mathrm{h}(\mathrm{n}=18)$ and the respiration rate averaged $-.064 \pm 0.026 \mathrm{mg} 0_{2} / \mathrm{mg}$ DW. $\mathrm{h}(\mathrm{n}=12)$. When $\mathrm{p}$-cresol was in association with Spirogyra in light and dark bottles, the net production of oxygen averaged only $0.022 \pm .091 \mathrm{mg}$ $\mathrm{O}_{2} / \mathrm{mg}$ DW. $\mathrm{h}$ for the three experiments combined $(\mathrm{n}=6)$. The respiration rate averaged $-0.182 \pm 0.116 \mathrm{mg} 0_{2} / \mathrm{mg} \mathrm{DW} . \mathrm{h}$

$(n=6)$. Figure 1 shows that photosynthetic rates decreased and respiration rates increased when the alga was incubated in p-cresol containing stream water. The effects of p-cresol on oxygen generation were less dramatic for experimental runs the afternoon of 25 August and the morning of 26 August. Because we noticed a temporal lightening of acidified water the morning of 25 August, we processed later experimental bottles within $1.5 \mathrm{~h}$ and kept all waiting bottles cool and in the dark. It is possible that organics and iron along with the p-cresol in the stream water made the Winkler method temporally less stable. Similar lightening of color after acidification was not observed for control bottles.

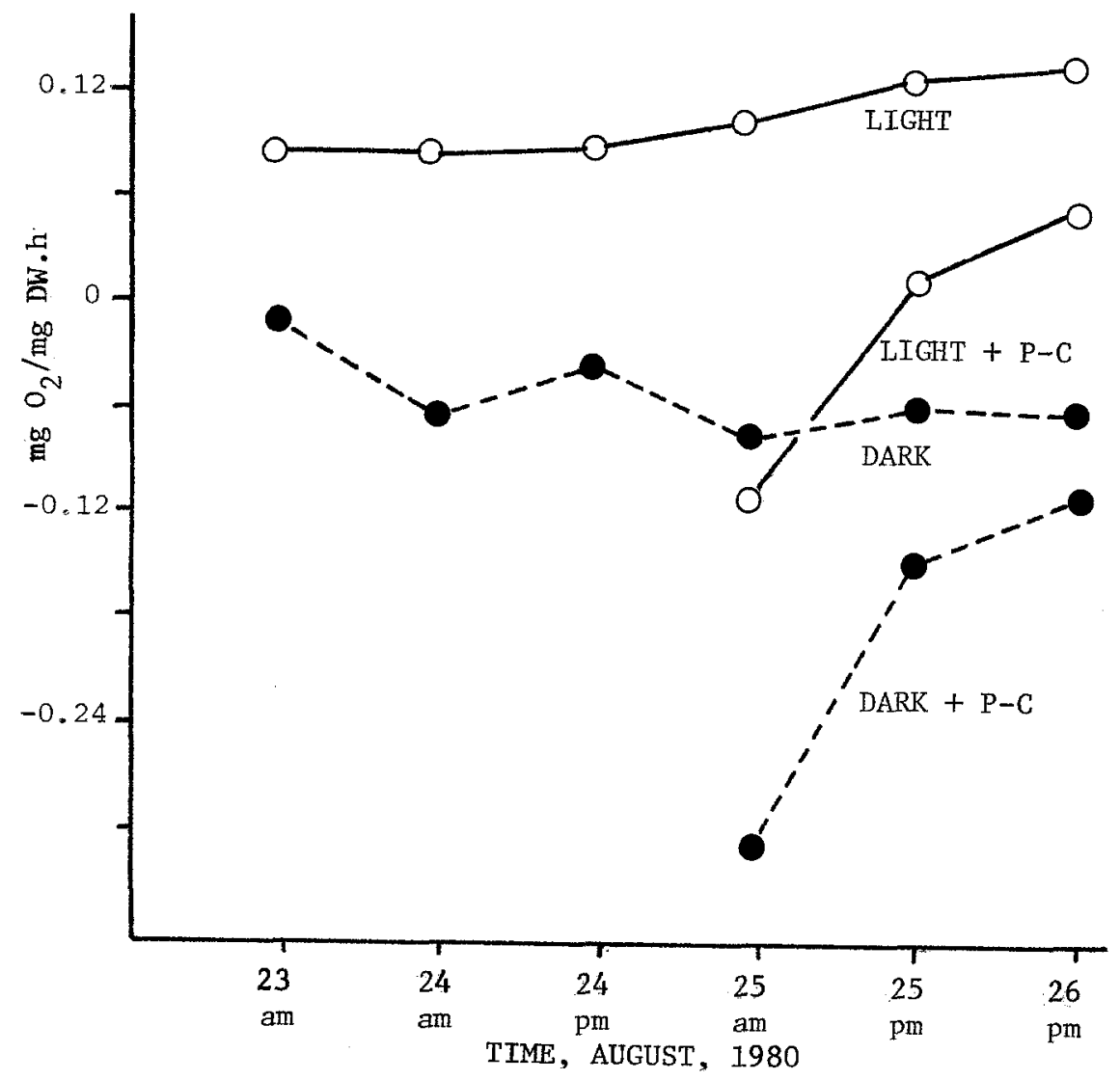

Fig. 1. Photosynthetic and respiration rates of Spirogyra sp. with and without p-cresol. Each point=mean 
Filtered and autoclaved water with and without p-cresol showed no differences in D.0. before versus after two hours of incubation time in light and dark bottles. Loss in D.0. occurred only in the presence of the alga with the p-cresol.

In the 1981 experiments where concentrations of p-cresol varied, D.0. dropped, after one hour's incubation, from a control value of $7.0 \mathrm{ppm}$ to $6.2,6.8,5.4,5.2$ and $5.6 \mathrm{ppm}$ for the following concentrations of p-cresol: $0.9,4.6,14,34$ and $71 \mathrm{ppm}$. The algae itself had turned brown in all but the control and two lowest concentrations of p-cresol containing water. Light and dark bottles were not used and photosynthetic and respiration estimates were not calculated.

\section{DISCUSSION}

GIDDINGS et a1. (1980) showed that water soluble fractions of coal liquification oils (which contained $4 \%$ phenols) inhibited photosynthesis of the green alga Selenastrum capricornutum even at $1 \%$ of the full concentration of the oil. 0ils from petroleum products (a 非 2 diesel fuel oil and a conventional \#6 oil) did not affect algal photosynthesis even at $10 \%$ of the full concentration. The authors suggest that the high content of phenolics in the coal-derived test oil was likely the toxicologically active ingredient.

Results of our studies, using one phenolic derivative, are compatible with those authors' findings; i.e., p-cresol at low concentrations, inhibited photosynthesis and increased algal respiration rates.

The mechanism underlying the physiological alterations in the alga is not known. However, there is considerable literature on the effect of phenolics on the physiology of aquatic plants (ELLIS 1977, ROSTYAEV 1972, BUIKEMA et al. 1979). It is known, for example, tht dinitrophenol uncouples photosynthesis from respiration, ultimately causing cellular death (BRONK 1973). HAUNG \& GLOYNA (1967) showed that growth rates of Chlorella pyrenoidosa can be inhibited in the presence of p-cresol when the toxicant is at concentrations greater than $50 \mathrm{ppm}$, and CHAMBERS et a1. (1963) showed that phenol and its three isomers, $\mathrm{m}-$, $\mathrm{o}^{-}$and $\mathrm{p}$-cresol had produced the highest oxygen uptake rates of 10 aromatic compounds tested for degradation rates by phenol-adapted bacteria.

Although these experiments did show that oxygen production by the major autotroph in the aquatic system was substantially reduced in the presence of p-cresol, the correlation between algal stress and lowered D.O. in the outdoor channel after being continuously dosed with p-cresol for $48 \mathrm{~h}$ (See COOPER \& STOUT 1982 for complete desription) cannot be linked to any causal factors intrinsic to the alga itself. We suggest, however, that any monitoring system where phenolics are potential aquatic toxicants should include dissolved oxygen analyses, as sudden drops in dissolved oxygen can have cascading effects on the entire aquatic ecosystem even when the original pollutant itself is only slightly toxic. 
Acknowledgements. This work was supported by an E.P.A. grant (No. R807555010) to R. H. Boling, Jr. and W. E. Cooper of Michigan State University and by a post-doctoral fellowship through the Michigan State University Agricultural Experiment Station (Journal Article No. 10600). We thank R. Boling, T. Burton, W. Cooper, R. Coleman, and R. Huggett for their comments on the manuscript and for discussions during the progress of the work.

\section{REFERENCES}

ALABASTER, J. S., D. CALAMARI, M. GRANDE, T. B. HASSELROT, R. LLOYD, V. MITROVIC' : Water Res. 7, 929. (1973).

BRONK, J. R.: Chemical Biology. An Introduction to Biochemistry. MacMillan, New York (1973).

BUIKEMA, A. L. JR., M. J. MCGINNISS, J. CAIRNS, JR.: Marine Environ. Res. 2, 87. (1969).

CHAMBERS, C. W., H. H. TABAK, P. W. KABLER: Water Pollut. Control Fed. 35, 1517. (1963).

COOPER, W. E. and R. J. STOUT: Assessment of transport and fate of toxic materials in an experimental stream ecosystem. In: Modeling the Fate of Chemicals in the Aquatic

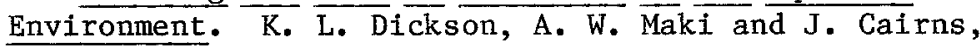
Jr., eds. Ann Arbor Science, Ann Arbor, MI (1982).

ELLIS, B. E.: Plant Sci. Lett. 8 , 213. (1977).

GIDDINGS, J. W., B. R. PARKHURST, C. W. GEHRS, R.W. MILLEMANN : Bul1. Environ. Contam. Toxico1. 25, 1. (1980).

HITCHMAN, M. I.: Measurement of Dissolved Oxygen. John Wiley \& Sons, Inc. and Orbisphere Labs, Geneva, Switzerland (1978).

HUANG, J-C, E. F. GLOYNA: Univ. Texas Ctr. for Res. in Water Res. Env. Health Eg. Res. Lab., Dept. Civil Eng. (1967).

KOSTYAEV, V. Y.: Trans. Inst. Biol. Vnutr. Vod. Akad. Nauk SSR. 24,98 . (1973).

SPENCER, D. F., M. J. GLUCKMAN, S. B. ALBERT: Science 215, 1571. (1982).

Accepted November 1, 1982 